\title{
BACTERIURIA ASINTOMÁTICA EN PACIENTES CON DIABETES
}

\author{
ASYTHOMATIC BACTERIURIA IN PATIENTS WITH DIABETES
}

\author{
Gloria Viñes ${ }^{1}$
}

\section{RESUMEN}

La bacteriuria asintomática (BA) se descubre con frecuencia en forma incidental mediante la realización rutinaria de análisis de orina. La prevalencia es tres a cuatro veces mayor en las pacientes con diabetes. Los factores de riesgo son la mayor duración de la diabetes, neuropatía periférica, macroalbuminuria, menor índice de masa corporal y un evento de infección urinaria del tractor urinario (ITU) previo. El diagnóstico de BA es el aislamiento de una cantidad especificada de colonias de una bacteria en muestras de orina, de un individuo sin signos o síntomas de ITU. La Escherichia coli y bacterias gram negativas son las más frecuentes. Se sugiere no tratar la BA en mujeres diabéticas con buen control metabólico, independientemente de la aparición de piuria. No debería hacerse pesquisa de bacteriuria ni tratamiento en pacientes diabéticos asintomáticos con buen control metabólico, excepto en embarazadas, con procedimientos urológicos y receptores de trasplante renal.

Palabras clave: bacteriuria asintomática; piuria; diabetes.

Revista de la Sociedad Argentina de Diabetes 2019; Vol. 53 (28-50)

\begin{abstract}
Asymptomatic bacteriuria $(A B)$ is often discovered incidentally by performing routine urinalysis. The prevalence is three to four times higher in patients with diabetes. The risk factors are the longer duration of diabetes, peripheral neuropathy, macroalbuminuria, lower body mass index and a previous urinary tract infection (UTI) event. The diagnosis of $A B$ is the isolation of a specified number of colonies of a bacterium in urine samples from an individual without signs or symptoms of UTI. Escherichia coli and gram-negative bacteria are the most frequent. It is suggested not to treat $A B$ in women with diabetes with good metabolic control, regardless of pyuria onset. Bacteriuria and treatment should not be studied in asymptomatic diabetic patients with good metabolic control, except pregnant women, with urological procedures and kidney transplant recipients.
\end{abstract}

Key words: asymptomatic bacteriuria; pyuria; diabetes.

Revista de la Sociedad Argentina de Diabetes 2019; Vol. 53 (28-50)
Médica especialista en Nutrición especializada en Diabetes, Jefa del Servicio de Nutrición y Diabetes del Hospital Privado de Comunidad, Ciudad de Mar del Plata, Provincia de Buenos Aires, Argentina

Contacto de la autora: Gloria Viñes

E-mail: vinesgloria@gmail.com

Correspondencia: Córdoba 4545, (B7602) Mar del Plata,

Buenos Aires
Fecha de trabajo recibido: 25/03/19

Fecha de trabajo aceptado: 03/04/19

Conflictos de interés: la autora declara haber recibido honorarios por conferencias, almuerzos de trabajo, participación en ensayos clínicos y financiación para asistencia a Congresos de Servier, Boehringer Ingelheim, Novartis, Merck Sharp \& Dohme, Sanofi Aventis, Bayer, Novo Nordisk y AstraZeneca.
La orina, que normalmente es estéril, también puede ser un buen medio para el crecimiento de bacterias que entran a la vejiga y no se eliminan.

La obtención de muestras de orina no contaminadas es difícil por lo que se estableció un umbral cuantitativo para distinguir si la bacteriuria proviene de la vejiga o de contaminación de la uretra.

\section{Epidemiología}

\section{Prevalencia y factores de riesgo}

A raíz de la realización de rutina de análisis de orina para la búsqueda de albuminuria en pacientes diabéticos, a menudo nos conduce al descubrimiento incidental de bacteriuria asintomática (BA).

En una revisión, Zhanel et al. observaron que la mayoría de los investigadores encontró una prevalencia de BA de aproximadamente tres a cuatro veces mayor en las pacientes diabéticas que en las no diabéticas, mientras que entre los hombres no hubo diferencia entre diabéticos y no diabéticos?.

Geerlings et al., en el Grupo de Estudio de Bacteriuria Asintomática, al buscar la prevalencia y factores de riesgo para BA en diabéticas y no diabéticas, hallaron que la prevalencia de BA en diabéticas fue del $26 \%$ y en los controles de $6 \%(p<0,001)$. La prevalencia de BA en diabéticas tipo 1 fue de $21 \%$. Los factores de riesgo para la mujeres con diabetes fueron la mayor duración de la diabetes, neuropatía periférica y macroalbuminuria. La prevalencia de BA en mujeres con diabetes tipo 2 fue de $29 \%$ y 
los factores de riesgo incluían edad, macroalbuminuria, menor índice de masa corporal y un evento de infección del tracto urinario (ITU) durante el año previo. No hubo asociación evidente entre el nivel de $\mathrm{HbA} 1 \mathrm{c}$ y la presencia de $\mathrm{BA}^{2}$.

En un estudio de cohorte prospectivo de 218 diabéticas y 799 mujeres postmenopáusicas no diabéticas se examinaron factores de riesgo para BA e ITU. El aumento del riesgo ocurrió principalmente en mujeres insulinotratadas (RR 3.7) y aquellas con más de 10 años de duración de la diabetes (RR 2.6), pero no hubo asociación entre BA y control de la glucemia ${ }^{3}$.

\section{Asociación con ITU}

Se estudió una gran cohorte de mujeres diabéticas en Holanda para determinar la incidencia de ITU sintomática. En mujeres diabéticas tipo 2, la presencia de BA en la línea de base aumentó el riesgo de subsiguiente ITU sintomática en un período de seguimiento de 18 meses del 19 al 34\%. La tasa de BA en esta población fue de aproximadamente el $28 \%$. Aún en la cohorte de diabéticas hubo más ITUs sintomáticas en las que tuvieron cultivos de orina negativos. Así el screening para evitar ITUs posteriores no fue costo-efectivo, incluso en esta población de alto riesgo 4 .

La diabetes mal controlada puede ser un factor de riesgo para ITU sintomática y complicaciones infecciosas ${ }^{5}$.

La prevalencia de piuria en diabéticos fue de casi el $80 \%{ }^{6}$, y la presencia y el grado de piuria no se asoció con el grado de infección sintomática?.

\section{Diagnóstico}

BA es el aislamiento de una cantidad especificada de colonias de una bacteria en muestras de orina recolectadas apropiadamente de un individuo sin signos o síntomas de ITU.

Los umbrales cuantitativos son distintos si se toma la muestra de orina del chorro medio o si la recolección se hace por cateterismo uretral.

La presencia de leucocituria ( $\geq$ a 10 leucocitos por $\mathrm{mm}^{3}$ de orina no centrifugada) no es suficiente para el diagnóstico de bacteriuria.

La definición de un cultivo de orina positivo es distinta en el contexto de síntomas de cistitis.

\section{Bacteriuria asintomática en mujeres}

Según la Infectious Diseases Society of America (IDSA) BA es el desarrollo del mismo gérmen en una muestra de chorro medio en dos urocultivos consecutivos, en mujeres asintomáticas que desarrollen $\geq 100.000$ UFC/m/8.

\section{Bacteriuria asintomática en hombres}

Definida por las guías de la IDSA como un sólo urocultivo positivo, más de 100.000 UFC/ml de una sola bacteria en ausencia de síntomas, tanto para muestras tomadas por chorro medio de la orina como por cateterismo uretral ${ }^{8}$.

\section{Microbiología}

La microbiología de la BA es similar a la de la cistitis y pielonefritis aunque algunas cepas en la BA pueden tener adaptaciones sutiles que facilitan la patogenia. Las cepas en la BA pueden ser menos virulentas y así no ser verdaderos patógenos. Escherichia coli y bacterias gram negativas son las más frecuentes.

\section{Pesquisa}

Tanto en pacientes diabéticos como no diabéticos debe realizarse pesquisa y tratamiento para BA en:

- Embarazadas en el primer y segundo trimestre del embarazo.

- Pacientes que se someterán a procedimientos urológicos.

- Pacientes receptores de transplante renal u otro órgano sólido en los tres primeros meses postransplante ${ }^{8}$.

\section{Tratamiento}

Se sugiere no tratar las BA en las mujeres con diabetes, no embarazadas, con buen control metabólico, aunque tengan piuria. Esta recomendación se basa en múltiples estudios que demuestran que el tratamiento con antibióticos no se asocia con la reducción de la infección sintomática y existe una alta tasa de recurrencia de bacteriuria una vez que se suspende la terapia con antibióticos ${ }^{9}$. Además la BA no se asoció con efectos adversos de la función renal ${ }^{10}$.

La presencia de piuria, la cual es reflejo de la inflamación del tracto genitourinario, se observa frecuentemente entre los pacientes con BA y diabetes, y no es indicación de tratamiento con antibióticos ya que no tiene significancia pronóstica?.

En la población diabética como no diabética, excluyendo los tres motivos anteriormente mencionados, el tratamiento de la BA con antibióticos no tiene beneficio clínico, se asocia a una alta 
tasa de recurrencia de BA y aumenta el riesgo de resistencia a los antibióticos ${ }^{10,11}$. Sin embargo, la diabetes mal controlada puede ser un factor de riesgo para ITU y complicaciones infecciosas, y en este caso se recomienda mantener un control más estricto y eventualmente aplicar tratamiento con antibióticos. Si se realiza tratamiento debería hacerse un urocultivo posterior para asegurar el éxito del mismo ${ }^{5}$.

En resumen la BA ocurre cuando en mujeres asintomáticas, no embarazadas, en dos muestras consecutivas de orina estéril se aísla el mismo germen que desarrollen $\geq$ a $100.000 \mathrm{UFC} / \mathrm{ml}$ y en hombres un solo urocultivo positivo, más de 100.000 UFC/ml de una sola bacteria en ausencia de síntomas, tanto para muestras tomadas por chorro medio de la orina como por cateterismo uretral.

En la mujeres diabéticas hay un aumento de bacteriuria de tres a cuatro veces (18 vs $6 \%$ ).

Los factores de riesgo en pacientes diabéticos son: insulinotratados (RR 3.7) y los que tienen más de 10 años de duración de la diabetes (RR 2.6).

Se sugiere no tratar la BA en mujeres diabéticas con buen control metabólico, independientemente de la aparición de piuria.

No debería hacerse pesquisa de bacteriuria ni tratamiento en pacientes diabéticos asintomáticos con buen control metabólico, excepto en embarazadas, procedimientos urológicos y receptores de trasplante renal.

\section{BIBLIOGRAFÍA}

1. Zhanel GG, Harding GK, Nicolle LE. Asymptomatic bacteriuria in patients with diabetes mellitus. Rev Infect Dis 1991; 13(1):150-4.

2. Geerlings SE, Stolk RP, Camps MJ, et al. Asymptomatic bacteriuria may be considered a complication in women with diabetes. Diabetes Mellitus Women Asymptomatic Bacteriuria Utrecht Study Group. Diabetes Care 2000; 23(6):744-9.

3. Boyko EJ, Fihn SD, Scholes D, et al. Risk of urinary tract infection and asymptomatic bacteriuria among diabetic and nondiabetic postmenopausal women. Am J Epidemiol 2005; 161(6):557-64.

4. Geerlings SE, Stolk RP, Camps MJ, et al. Consequences of asymptomatic bacteriuria in women with diabetes mellitus. Arch Intern Med 2001; 161(11):1421-7.

5. Grabe M, Bartoletti R, Bjerklund-JohansenTE, CaiT (Guidelines Associate), Çek M, Köves B (Guidelines Associate), Naber KG, Pickard RS, Tenke P, Wagenlehner F, Wullt B. Guidelines on Urological Infections. European Association of Urology 2015.

6. Zhanel GG, Nicolle LE, Harding GK. Prevalence of asymptomatic bacteriuria and associated host factors in women with diabetes mellitus. The Manitoba Diabetic Urinary Infection Study Group. Clin Infect Dis 1995; 21(2):316-22.

7. Zalmanovici-Trestioreanu A, Lador A, Sauerbrun-Cutler MT, Leibovici L. Antibiotics for asymptomatic bacteriuria. Cochrane Database Syst Rev 2015; 4:CD009534.

8. Nicolle LE, Bradley S, Colgan R, et al. Infectious Diseases Society of America guidelines for the diagnosis and treatment of asymptomatic bacteriuria in adults. Clin Infect Dis 2005; 40(5):643-54.

9. Harding GK, Zhanel GG, Nicolle LE, et al. Antimicrobial treatment in diabetic women with asymptomatic bacteriuria. N Engl J Med 2002; 347(20):1576-83.

10. Meiland R, Geerlings SE, Stolk RP, et al. Asymptomatic bacteriuria in women with diabetes mellitus: effect on renal function after 6 years of follow-up. Arch Intern Med 2006; 166:2222-7.

11. Cai T, Nesi G, Mazzoli S, et al. Asymptomatic bacteriuria treatment is associated with a higher prevalence of antibiotic resistant strains in women with urinary tract infections. Clin Infect Dis 2015; 61(11):1655-61. 